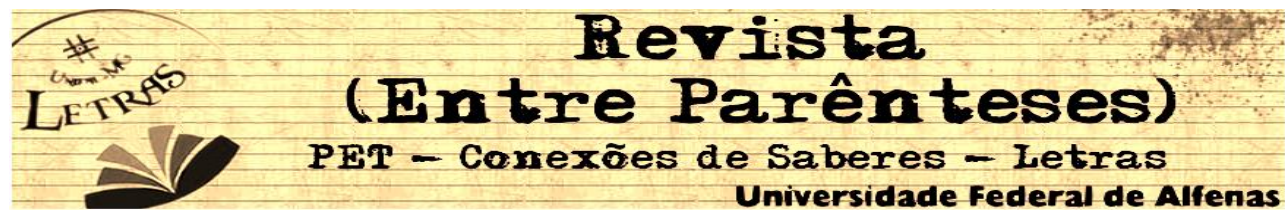

\title{
A PESQUISA NO PROCESSO DE FORMAÇÃO DO PROFESSOR DE PORTUGUÊS: UM ESTUDO DE CASO DO PROGRAMA PIBID/LETRAS/UFLA
}

\author{
Leonardo de Oliveira \\ Universidade Federal de Lavras \\ loliveira@lavras.mg.gov.br \\ Helena Maria Ferreira \\ Universidade Federal de Lavras \\ helenaferreira@dch.ufla.br
}

\begin{abstract}
RESUMO: Este artigo ocupa-se de uma temática pouco estudada no meio acadêmico, qual seja, a pesquisa no processo de formação do professor. Nesse sentido, a presente investigação tem como objetivo principal inventariar as contribuições da prática da pesquisa na licenciatura em Letras, de modo mais específico, no Programa Institucional de Bolsas de Iniciação à Docência (CAPES/DEB), executado pelo Curso de Letras da Universidade Federal de Lavras (MG). Foi realizado um estudo teórico, com vistas a compilar estudos sobre a importância da pesquisa na formação de professores. Os resultados apontaram para uma aquisição de uma atitude investigativa acerca de questões teóricas, metodológicas e operacionais subjacentes à prática educativa. Nesse sentido, foram observadas duas questões básicas: a necessidade de uma sistematização da atividade de pesquisa nas licenciaturas e o reconhecimento dessa prática na aquisição de habilidades e competências substanciais à atuação docente. Foi realizada uma pesquisa de campo, a partir de questionários aplicados a bolsistas do PIBID. Os resultados desvelaram possibilidades de implantação de espaços de reflexão sobre conceitos e procedimentos necessários à formação teórica e metodológica de um professor de língua portuguesa. Foram apontadas questões que podem contribuir para a sistematização ou para o redimensionamento das ações do Projeto PIBID.
\end{abstract}

Palavras-chave: formação docente; pesquisa; PIBID.

RESUMEN: En este artículo se aborda un tema poco estudiado en la academia, a saber, la investigación en el proceso docente educativo. En este sentido, la presente investigación tiene como objetivo estudiar las principales aportaciones de la investigación en la práctica en las Cartas de grado, más concretamente, el Programa de Becas de Iniciación a la Docencia (CAPES / DEB), dirigido por el Curso de Letras de la Universidad Federal Lavras (MG). Llevamos a cabo un estudio teórico, con el fin de recopilar estudios sobre la importancia de la investigación en la formación docente. Los resultados apuntan a una adquisición de una actitud investigadora sobre asuntos teóricos, metodológicos y operativos relacionados a práctica educativa. En consecuencia, observamos dos cuestiones básicas: la necesidad de la sistematización de las actividades de investigación en reconocimiento de grado y de esta práctica en la adquisición de habilidades y 


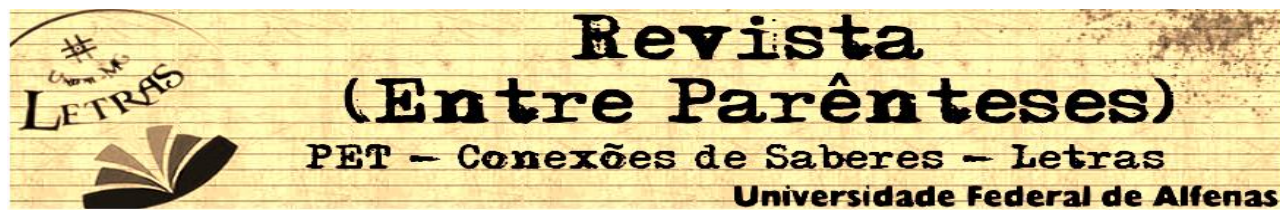

competencias para el desempeño docente sustancial. Hemos llevado a cabo un estudio de campo a partir de cuestionarios entregados a los becarios Pibid. Los resultados dio a conocer las posibilidades de implementación de espacios para la reflexión sobre los conceptos y procedimientos necesarios para la formación metodológica y teórica de un profesor de lengua portuguesa. Temas han sido identificados que pueden contribuir a la sistematización o cambiar el tamaño del proyecto Pibid acciones.

Palabras clave: formación docente, investigación, Pibid.

\section{Introdução}

A proposta do presente trabalho é apresentar as contribuições que a inserção das atividades de pesquisa nas rotinas das licenciaturas em Letras pode trazer à formação dos graduandos e como tais contribuições se refletem nas concepções acerca da língua e de seu ensino. Com vistas às implicações que a adoção dessa prática traz à futura atuação dos graduandos, este estudo pretende debruçar-se sobre as peculiaridades inerentes ao processo de pesquisa para então compreender os meios pelos quais o envolvimento do licenciado em atividades dessa natureza se traduz numa formação mais ampla, aprofundada e, em consequência, norteadora de uma atuação mais produtiva e eficaz na sala de aula. A partir dessas discussões, parte-se para um estudo de caso feito com os bolsistas PIBID da UFLA, durante o qual foi aplicado um questionário com $\mathrm{o}$ intuito de avaliar em que medida o desenvolvimento de pesquisas por tais bolsistas trouxe contribuições à formação acadêmica bem como à execução das tarefas no âmbito do referido programa.

\section{Formação do professor}

Constata-se em várias instâncias da educação uma ideia de que o papel do professor é o de pura e simplesmente repassar 


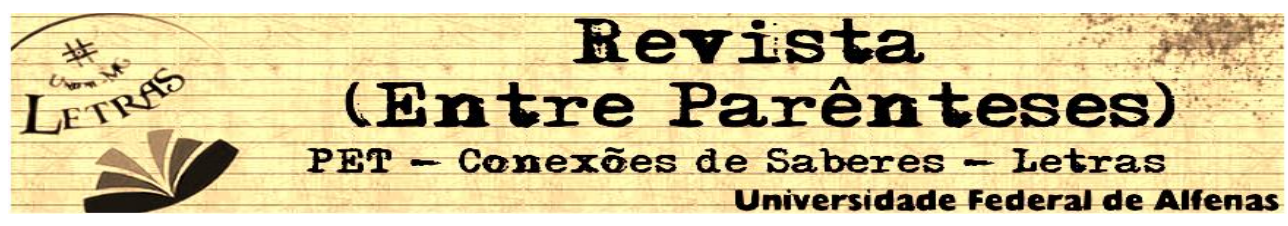

aos seus alunos conteúdos que adquiriu na graduação da maneira como o aprendeu. Por extensão, a sociedade também atribui a este profissional o mesmo encargo e enxerga no bom professor a capacidade de transmissão da maior quantidade possível de informação ao aluno. Assim, vigora uma noção generalizada de que cabe ao docente exclusivamente "fazer o aluno saber o que ele, professor, sabe" (HAWAD, 2009). Essa histórica postura coloca o aluno na condição de mero espectador, passivo e subserviente, a quem só é aberta a oportunidade de se manifestar quando há alguma dúvida quanto ao que lhe é ensinado. O professor, por outro lado, detentor do conhecimento, atua como uma espécie de dono das verdades que ensina e desempenha autoritariamente as suas referidas atribuições. Sobre a questão, Demo (1996, p. 76) afirma que o professor assim formado deseja o aluno que não questiona, pois dessa forma não corre o risco de ter a fragilidade da sua formação exposta. O aluno, tratado como mero repositório de informação, constrói as suas concepções quanto aos conteúdos que aprende, que geralmente não fazem sentido algum para ele, e quanto às atribuições do professor, o que acaba por fazer com que representações estreitas sobre a função do professor sejam perpetuadas. Ainda no que concerne à questão, Demo pondera que

A aula que apenas repassa conhecimento, ou a escola que somente se define como socializadora de conhecimento, não sai do ponto de partida e, na prática atrapalha o aluno, porque o deixa como objeto de ensino e instrução. Vira treinamento. É equívoco fantástico imaginar que o "contato pedagógico" se estabeleça em ambiente de repasse e cópia, ou na relação aviltada de um sujeito copiado (professor, no fundo também objeto, se apenas ensina a copiar) diante de um objeto apenas receptivo (aluno), condenado a escutar aulas, tomar notas, decorar, e fazer prova. A aula copiada não constrói nada de distintivo, e por isso não educa mais do que a fofoca, a conversa fiada 


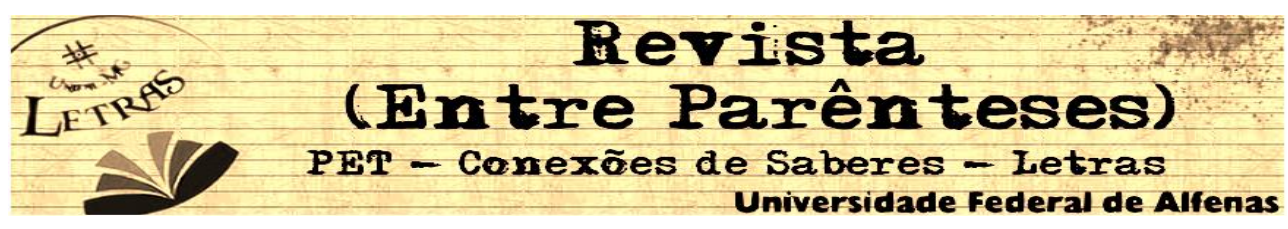

dos vizinhos, o bate-papo numa festa animada. ( $p$. 7)

Devotado à investigação de questões acerca da importância de se associar a pesquisa ao ensino, o autor supracitado afirma que, ao contrário do que muitos pensam, a pesquisa é o principal meio pelo qual a educação deve se dar, o que não deve, no entanto, significar a abolição da aula. Pelo contrário, a proposta de se educar por meio da pesquisa é pensada pelo autor como uma iniciativa a ser desenvolvida justamente na aula, numa postura de conciliação dos dois expedientes. A pesquisa, nesse sentido, irá pautar toda a dinâmica da aula, diversificando-a, enriquecendo-a e estimulando o aluno a pensar por si mesmo, a se conhecer e a conhecer o mundo de maneira participativa. Assim, postula que a proposta de educação pela pesquisa se apóia em quatro pilares:

- a convicção de que a educação pela pesquisa é a especificidade mais própria da educação escolar e acadêmica,

- o reconhecimento de que o questionamento reconstrutivo com qualidade formal e política é o cerne do processo de pesquisa,

- a necessidade de fazer da pesquisa atitude cotidiana no professor e no aluno,

- e a definição de educação como processo de formação da competência histórica humana. (1996, p.5)

Tais pilares impõem uma reflexão acerca dos fatores que levam as práticas educacionais à condição na qual hoje se encontram. Nesse sentido, é fundamental que se leve em consideração a formação docente. É notória a pouca atenção que grande parte dos cursos de graduação dá à prática da pesquisa, especialmente aqueles oferecidos pelas faculdades particulares. E, ainda que nas universidades públicas o incentivo a tais práticas seja 


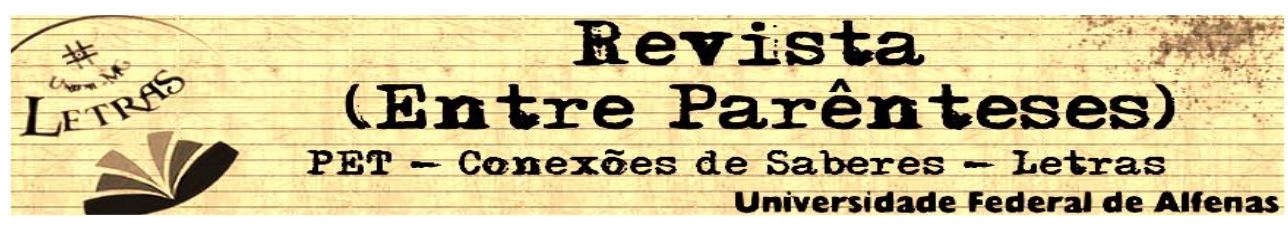

maior, elas são predominantemente desenvolvidas em cursos de bacharelado. Há uma ideia generalizada de que às licenciaturas cabe apenas ensinar os conteúdos específicos de uma dada área e aspectos pedagógicos do ensino desses conteúdos, o que resulta em visões distorcidas sobre o que é ministrar aulas (LÜDKE, 2001). Se se considerar que as representações que alguns docentes têm sobre a língua e sobre o seu ensino se convertem em ações na sala de aula, fica clara a compreensão de que há graduações em Letras que não se dão conta do quanto a pesquisa pode elevar a formação docente e a atuação profissional a um patamar mais reflexivo e crítico. De acordo com o Parecer CNE/CP $\mathrm{n}^{\circ} 1$ de 18 de fevereiro de 2002, apud ANDRÉ, 2002, p. 66).

A pesquisa constitui um instrumento de ensino e um conteúdo de aprendizagem na formação, especialmente importante para a análise dos contextos em que se inserem as situações cotidianas da escola, para construção de conhecimentos que ela demanda e para compreensão da própria implicação na tarefa de educar.

Almeida Filho (2005) corrobora a questão ao afirmar que a experiência universitária deve promover, antes de tudo, a ampliação da cultura geral e o aprofundamento de conteúdos (p. 2), bem como basear-se

na familiarização com a leitura, na interação oral através de textos orais e seus "autores", na observação aguda, na análise das partes, interpretação criteriosa dos dados, busca de sínteses, relações mais complexas e eventualmente merece propostas de solução das questões e/ou encaminhamentos fundamentados (p. 3). 


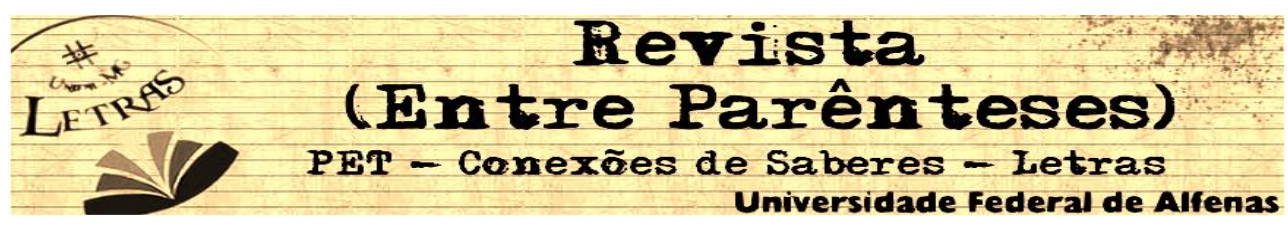

Isso certamente evidencia os potenciais benefícios que a pesquisa pode trazer à formação acadêmica, já que uma graduação assim conduzida torna o graduando uma pessoa mais crítica, autônoma e ciente tanto de questões específicas da sua área quanto de outras de caráter generalizado do mundo ao seu redor, o que se converte em atitudes políticas responsáveis, lúcidas e capazes de, por meio do conhecimento, colaborar de alguma forma para a melhoria do meio em que se vive. Portanto, é justamente nos acarretamentos dessa conduta que está valor da pesquisa, pois, segundo o autor,

o exercício do método científico de (re)elaboração do conhecimento permite que se possa enxergar por detrás das experiências, através da crítica (da dúvida, do questionamento, do recurso a critérios explícitos) e, eventualmente, se chegar a alguma forma de (inov)ação transformadora. (p. 3)

Outra importante contribuição à discussão pode ser encontrada nos estudos de Soares (2002), que, partindo de um exemplo prático, explicita que uma ação eficaz do professor na classe, que atenda às reais necessidades de seus alunos, requer uma perspicácia que somente a sua vivência, ainda enquanto graduando, em processos de produção do conhecimento pode proporcionar. Assim como os demais autores aos quais aqui se faz referência, Soares (p. 102) destaca que não se pode deixar de entender a pesquisa e o ensino como indissociáveis entre si. Em outras palavras, é preciso que se alie a produção do conhecimento à socialização do conhecimento. A familiarização com os procedimentos por meio dos quais se produz conhecimento é capaz de dotar o graduando dos requisitos necessários à sua futura atuação como professor, uma vez que, por sua natureza, tal processo exige, em primeiro lugar, o aprofundamento em conteúdos 


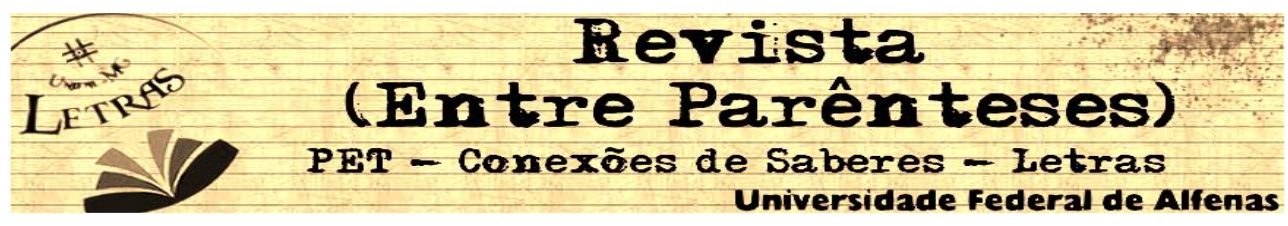

específicos por meio do inventário de referenciais teóricos e, depois, que se consiga explicar os fenômenos sobre os quais se deseja investigar a partir dos muitos conceitos que esse referencial abarca. Esse processo, além demandar múltiplas leituras e capacidade de abstração, amplia e aprofunda a base teórica do graduando, tornando-o mais estimulado a encarar as suas experiências acadêmicas por meio de uma postura de questionamento, de investigação, que deve, obviamente, se estender a sua posterior atuação na escola.

Visando a promover a compreensão da questão em termos práticos, Soares lança mão de um exemplo extremamente pertinente aos fins deste trabalho. Tomando como objeto de análise uma pequena narrativa produzida por um aluno em fase de aquisição da escrita, a autora elenca uma série de ocorrências que poderiam se tornar objeto de pesquisa. Entre as tais, a autora menciona a ausência das letras $m$ e $n$ em várias das palavras da narrativa que possuem sons nasais. Partindo dessas ocorrências, Soares afirma que, para que um professor tenha clareza quanto à natureza desse fenômeno e quanto à conduta que deve adotar nessa situação de modo a trabalhá-la com o aluno, é fundamental que, na sua graduação, tenha constituído uma base sólida em conhecimentos linguísticos, especialmente no que diz respeito à Fonética. Porém, esse corpo de conhecimentos não pode estar edificado apenas sobre a simples leitura de referenciais teóricos, mas decorrer do envolvimento em investigações que se traduza na condição de formular hipóteses bem fundamentadas para a explicação da ocorrência e na possibilidade de agir com competência sobre o caso.

Em resumo, Soares mostra que toda a bagagem teórica e prática, bem como a criticidade e a visão ampliada que a experiência com pesquisa proporciona, devem desenvolver no docente a 


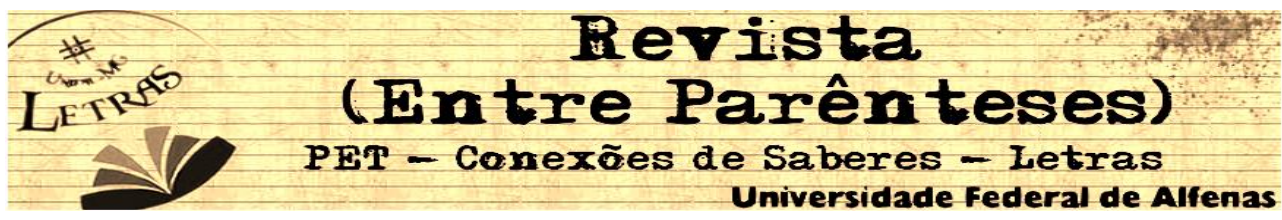

capacidade de "compreender e avaliar o uso que o aluno faz da língua ao construir o seu texto: em que condições escreve, para que e para quem escreve, que representação tem do interlocutor, que função atribui à sua escrita." (p. 98).

Complementando o exposto, Fazenda (2005), considera que a pesquisa pode favorecer a formação de um professor capaz de reconstruir o próprio processo de formação e de atuação docente, capaz de perceber as teorias como imperfeitas e incompletas, de duvidar de suas intercorrências práticas decorrentes de uma dúvida maior - "a de que algo de sua prática vivida possa estar contribuindo para a explicitação das imperfeitas teorias sobre educação já construídas bem como da beleza das que se tornaram clássicas." Dessas indagações e da busca de respostas surge o desafio de criar teoria, uma teoria nascida de uma prática intensamente vivida.

Nesse contexto, Lüdke (2001) considera que um profissional atualizado e reconhecedor do seu papel como produtor de conhecimento favorece um preparo mais adequado para o contexto da sala de aula. Uma postura inquiridora, própria de um pesquisador amplia a reflexão sobre os saberes teóricos e sobre a prática docente.

Freire (2008, p. 29) é enfático:

Não há ensino sem pesquisa e pesquisa sem ensino. Esses quefazeres se encontram um no corpo do outro. Enquanto ensino, continuo buscando, reprocurando. Ensino porque busco, porque indaguei, porque indago e me indago. Pesquiso para constatar, constatando intervenho, intervindo educo e me educo. Pesquiso para conhecer o que ainda não conheço e comunicar ou anunciar a novidade. 


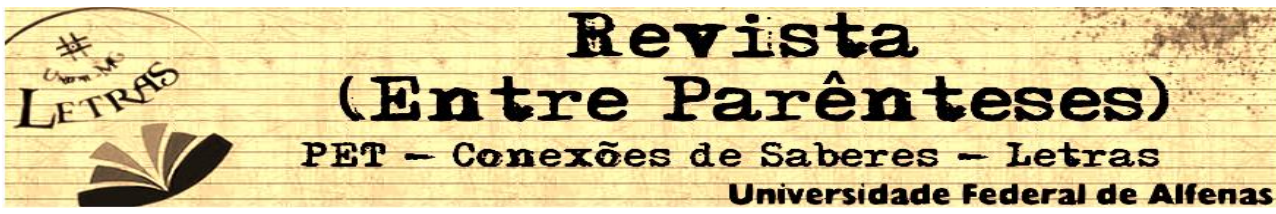

Diante dessas pontuações, é possível admitir que a prática da pesquisa assume importância substancial tanto na formação, quanto na atuação do professor.

\section{Análise dos dados}

Em complemento à pesquisa teórica empreendida, foi realizada uma investigação para qual foi aplicado um questionário com os bolsistas PIBID/Letras da Universidade Federal de Lavras. O objetivo da aplicação do mesmo foi avaliar quais as posições desses alunos no que diz respeito à prática da pesquisa no decorrer do referido projeto. Respondidos por vinte e sete dos trinta bolsistas do programa, os questionários são constituídos de quatro perguntas abertas cujas respostas fornecem importantes subsídios à compreensão acerca das implicações inerentes à inserção desses graduandos em atividades de pesquisa sobre a prática pedagógica.

Antes de se discutir as respostas obtidas, é importante ressaltar que todas as atividades aplicadas em sala de aula pelos bolsistas são embasadas em referenciais teóricos previamente levantados e sistematicamente discutidos em oficinas, grupos de estudo e seminários. Além dos estudos teóricos, os bolsistas são orientados em investigações de campo desenvolvidas a partir das atividades realizadas por eles nas escolas.

O questionário inicia-se com a seguinte pergunta: Quais foram os temas sobre os quais você já pesquisou como proposta de trabalho acadêmico no PIBID? Dezesseis temas distintos figuram entre as respostas. Em maior ou em menor grau, quase todos os temas se referem a tópicos tradicionalmente negligenciados pela escola em detrimento de abordagens que privilegiam o normativismo da gramática tradicional. $A$ atenção dada 


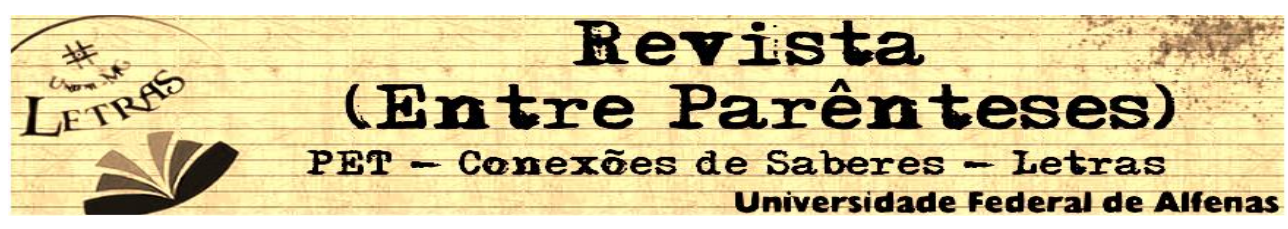

a tais temas no projeto demonstra uma ênfase em trabalhos desenvolvidos com base em conhecimentos que são produto das pesquisas se vêm realizando atualmente na lingüística que, além de trazerem novas formas de se entender a língua, são capazes de atender às verdadeiras necessidades dos alunos da educação básica. Entre os temas trabalhados pelos bolsistas, os mais recorrentes são o dos gêneros textuais $(31,88 \%)$, o da oralidade $(28,98 \%)$ e o das atividades de leitura (11,59\%). Tais temas, com exceção da leitura, são tópicos ainda pouco trabalhados na escola, cuja compreensão depende de se estar a par dos avanços que a linguística tem feito nesses campos, o que requer que se pesquise e se coloque em prática os seus pressupostos. Nessa medida, as condutas adotadas no âmbito do PIBID vão ao encontro às ideias de Soares (2001) quanto à questão, já que, segundo afirma,

a influência da pesquisa na formação do professor estará [...] na possibilidade de, pela convivência com a pesquisa e, mais que isso, da vivência dela, o professor apreender e aprender os processos de produção do conhecimento em sua área específica. Porque é apreendendo e aprendendo esses processos, mais do que apreendendo e aprendendo os produtos desse conhecimento em sua área específica, que o professor estará habilitado a ensinar, atividade que deve visar, fundamentalmente, aos processos de aquisição do conhecimento, não apenas os produtos. (p. 101)

Como se pode observar, as atividades desenvolvidas pelo Programa contribuem para o início de uma mudança do perfil do ensino de línguas, ainda que de maneira incipiente. Dessa forma, o enfoque está na abordagem de temas que precisam ser inseridos no ensino da língua e que, sendo frutos de processos com os quais os bolsistas precisam se familiarizar, podem ser estendidos a trabalhos que visem não só a apreensão de como se faz pesquisa na 


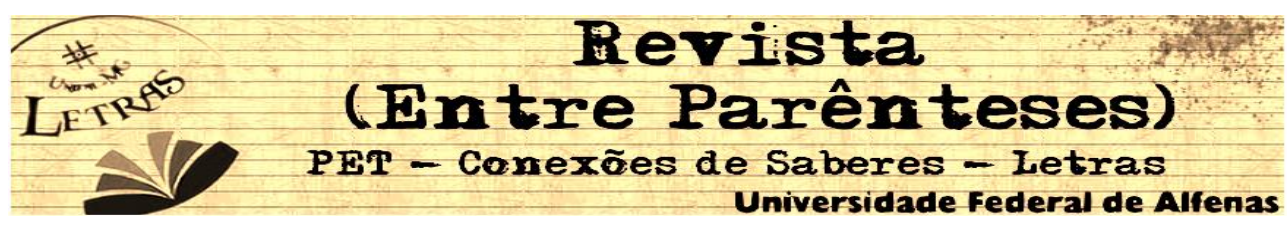

graduação, mas de como se instaurar o espírito investigativo no cotidiano dos ensinos fundamental e médio. Como o programa PIBID funciona por meio da parceria entre os professores das escolas públicas participantes e os da universidade, juntamente com os graduandos, é importante que essa cooperação também aconteça de modo a fomentar a mudança da concepção de escola hoje vigente. Nesse intuito, a mudança significaria repensar o que se entende por aula, numa postura em que, para Demo (1996), "é essencial desfazer a noção de "aluno" como sendo alguém subalterno, tendente a ignorante, que comparece para escutar, tomar nota, engolir ensinamentos, fazer provas e passar de ano" ( $p$. 15). Ao mesmo tempo, o autor enfatiza os aspectos cidadão e político do aluno formado através da educação pela pesquisa como fator indispensável ao modelo de educação que se pretende construir. É nessa direção que Demo (1996, p. 15) aponta ao dizer que, ter em vista a formação de uma sociedade cidadã, requer que o fomento do espírito de pesquisa na vida escolar se traduza na participação do aluno enquanto parceiro verdadeiramente atuante nos trabalhos realizados, onde o professor deve agir como um motivador do aluno.

As respostas à primeira pergunta mostram uma significativa conscientização dos graduandos quanto à importância de se entender a produção e a socialização do conhecimento como importante para a melhor compreensão da língua e de como ensinála.

Com relação à segunda pergunta, ficam novamente exaltadas as questões que aparecem na primeira. Dividida em três subitens, pede-se primeiramente o seguinte: Escreva uma contribuição que a prática da pesquisa tem trazido a(ao): a) Seu desempenho como aluno de graduação. Aqui, as respostas desse subitem foram agrupadas em doze categorias, das quais destacam- 


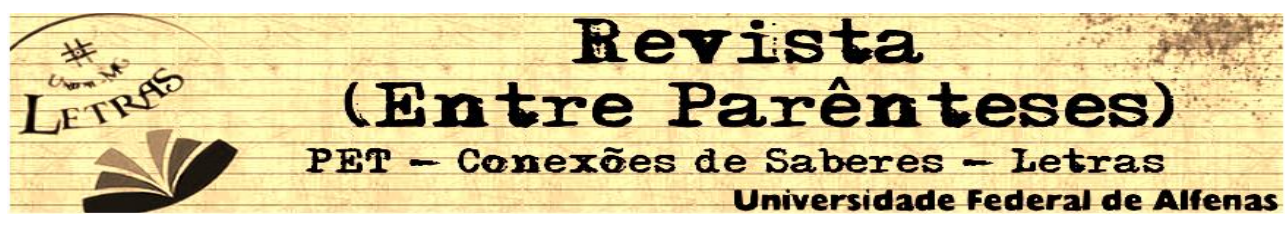

se as três de maior ocorrência, sendo elas a de maior conhecimento sobre a língua (18,60\%), a de preparação/competência profissional $(18,60 \%)$ e a de maior criticidade (13,95\%). Além de novamente evidenciarem que há itens que o ensino básico insiste em não abordar, manifestados inclusive pelo caráter de novidade com que tais práticas são apresentadas aos próprios bolsistas do projeto, essas respostas indicam o impacto que as abordagens calcadas na pesquisa podem exercer na formação inicial dos licenciandos e na futura atuação como docentes.

O subitem $b$, Escreva uma contribuição que a prática da pesquisa tem trazido a/ao: b) Sua atuação nas atividades desenvolvidas no PIBID:, suscita ao generalizado descaso com o qual a pesquisa tem sido tratada na escola e em muitas graduações. Das oito respostas que ocorreram, a aquisição de noções teóricas e metodológicas $(35,48 \%)$ aparece em primeiro lugar, seguida do entendimento acerca da função do professor de português (12,90\%) e da segurança (12,90\%). Esse é, na verdade, o subitem que mais nos remete a todas as questões discutidas até então, afinal, reflete a carência de uma familiarização dos graduandos com requisitos basilares da educação que se pretende pautar na pesquisa. Para Demo (1996), é preciso que os cursos de graduação formem professores que tenham a clareza de que "tratando-se do ambiente escolar, prevalece a pesquisa como princípio educativo, ou o questionamento reconstrutivo voltado para a educação do aluno" ( $p$. 38).

O terceiro subitem da pergunta dois pede: Escreva uma contribuição que a prática da pesquisa tem trazido a/ao: c) Sua formação como professor. De caráter um pouco mais genérico, as respostas dadas a essa questão reforçam o papel da pesquisa enquanto prática que proporciona um diferencial na formação dos graduandos que com ela se envolvem. Questões referentes à 


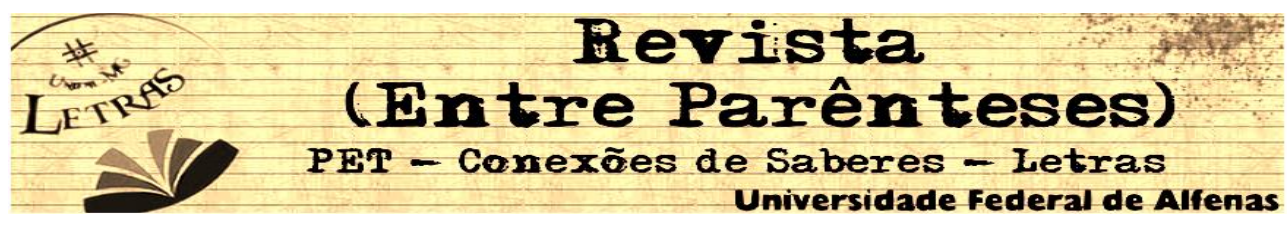

formação ampliada $(35,13 \%)$ foram as mais numerosas, seguidas da ampliação da experiência em sala de aula $(27,02 \%)$ e da capacidade de relacionar teoria e prática (24,32\%). Há ainda um item que, embora seja o menos frequente, sugere que as vivências dos bolsistas com a pesquisa têm suprido inclusive deficiências primárias como a dificuldade de escrita. Ou seja, isto remete à já discutida questão do quanto aprender e apreender os processos de produção de conhecimento (SOARES, p. 101) requer e, ao mesmo tempo, desenvolve certas habilidades que os membros do projeto já deveriam dominar quando do ingresso na graduação. As deficiências supracitadas também se fazem presentes nos dois últimos itens do questionário.

A terceira pergunta é: Destaque três dificuldades que você tem enfrentado no desenvolvimento de pesquisas no âmbito do PIBID. As respostas obtidas aqui foram reunidas em dezesseis itens, entre os quais aparecem alguns aspectos não estritamente ligados à pesquisa, mas ordem técnica como falta de tempo (21,15\%), a sobrecarga de atribuições dos orientadores $(9,61 \%)$ ou a falta de acervo sobre os temas pesquisados na biblioteca (9,61\%). As demais respostas relacionam-se à pouca familiarização dos bolsistas do Programa com a pesquisa e a formação por vezes deficitária que alguns deles tiveram, o que só vem a corroborar realidades da educação básica atual que a ideia de se educar por meio da pesquisa pretende combater. Assim, respostas como o desconhecimento teórico (7,69\%), desconhecimento metodológico (5,76\%) e dificuldade de compreensão dos textos teóricos $(3,84 \%)$ reafirmam tais deficiências da educação básica e novamente apontam para a urgência de se mudar paradigmas.

Por fim, a respostas dadas à quarta e última pergunta indicam a necessidade dos bolsistas de intensificarem as suas Revista (Entre Parênteses) 


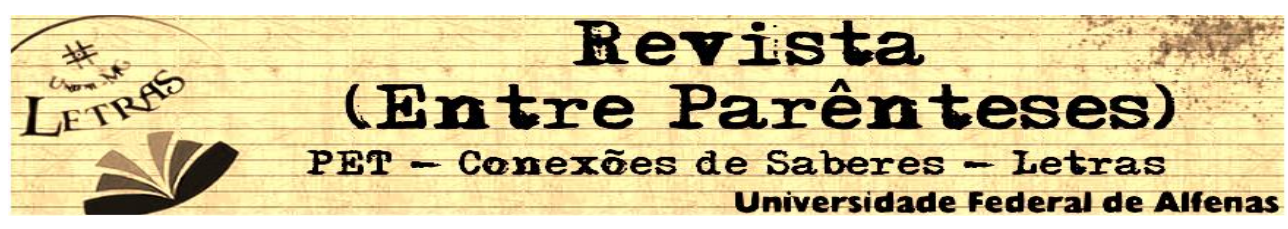

vivências com a pesquisa. Perguntou-se: Apresente três sugestões para tornar a prática da pesquisa mais efetiva e eficaz no âmbito do PIBID. Assim como na pergunta anterior, existem entre as respostas mais comuns as mesmas questões a respeito de aspectos de ordem técnica, porém, aparecem dessa vez com o caráter de sugestão ao projeto PIBID. Ademais, há novamente um enfoque em iniciativas que os levem ao domínio dos requisitos necessários à prática da pesquisa e do referencial teórico estudado. A criação de mais núcleos de estudo $(9,61 \%)$, a realização de mais oficinas $(9,61 \%)$ e a realização de mais pesquisas práticas $(5,76 \%)$ estão entre as mais recorrentes respostas diretamente ligadas ao tipo de atividade que desenvolvem. Tais respostas mais uma vez trazem à tona as exigências do processo de pesquisa e o reconhecimento dos bolsistas no que concerne aos benefícios da pesquisa nas suas vivências acadêmicas.

\section{Considerações finais}

Com base no referencial teórico levantado, foi possível constatar que a incorporação da pesquisa cotidiano da prática pedagógica, seja em que nível for, causa um impacto extremamente positivo, pois por um lado, alarga enormemente o horizonte cultural e intelectual do graduando e, por outro, beneficia a educação básica ao trazer para esse contexto o senso crítico quanto ao que é educação, a visão de mundo ampliada e a promoção da autonomia do discente.

Por sua vez, o estudo de caso feito com os bolsistas PIBID mostra que o envolvimento com pesquisas tem feito com que sejam abertas possibilidades para uma consolidação dos conteúdos 


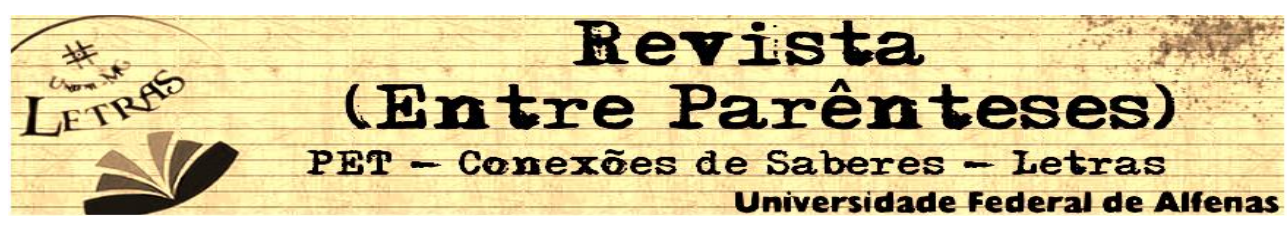

curriculares trabalhados nas diferentes disciplinas, para uma reflexão sobre a prática pedagógica, para uma troca de saberes. Todas essas questões são importantes, mas a principal delas consiste na construção de "uma atitude cotidiana de busca de compreensão dos processos de aprendizagem e desenvolvimento de seus alunos e à autonomia na interpretação da realidade e dos conhecimentos que constituem seus objetos de estudo (CNE/CP $\mathrm{n}^{\circ}$ 1 de 18 de fevereiro de 2002, apud ANDRÉ, 2002, p.67). No contexto da pesquisa empreendida, destaca-se, também, a possibilidade de minimizar dificuldades advindas da educação básica.

A investigação demonstra que tornar a pesquisa uma realidade na rotina de todos os níveis da educação pode começar a ser viabilizado pelo fomento à pesquisa nas licenciaturas, na formação inicial dos professores. Dessa forma, preparam-se professores com o potencial de criar entre os seus futuros alunos representações mais aprofundadas sobre a língua e o seu ensino e, com isto, começar a difusão de ideias que contribuam para a mudança da educação no todo.

\section{Referências bibliográficas}

ALMEIDA FILHO, J. C. P. A diferença que faz uma formação universitária aos alunos de graduação. In: LIMA, R. C. C. P. (Org.). Leitura: múltiplos olhares. Campinas: Mercado das letras, 2005. p. 103-110.

BRASIL. CONSELHO NACIONAL DE EDUCAÇÃO. Proposta de Diretrizes para a Formação Inicial de Professores da Educação Básica em Cursos de nível Superior. CNE/CP N ${ }^{\circ} 1$ de 18 de fevereiro de 2002. 


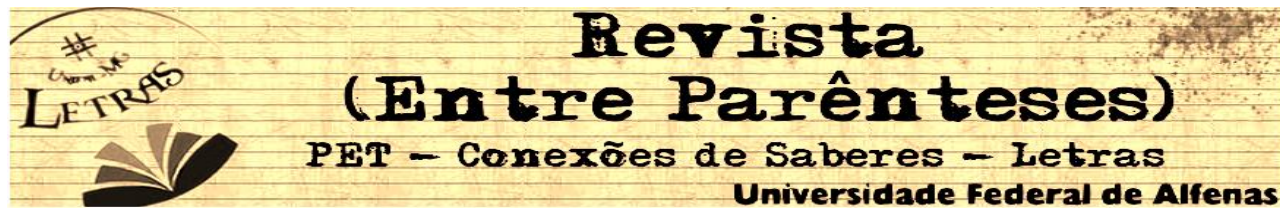

DEMO, P. Educar pela pesquisa. Campinas: Autores associados, 1996. 129 p.

FAZENDA, I. C.A. A formação do professor Pesquisador - 30 anos de Pesquisa. Revista E-Curriculum, São Paulo, v.1, n.1, dezjul.2005- 2006. Disponível em: <http://www.pucsp.br/ecurriculum> Acesso em 10 out. 2012.

FREIRE, Paulo. Pedagogia da autonomia: saberes necessários à prática educativa. 37. ed. São Paulo: Paz e Terra, 2008.

HAWAD, H. F. O ensino da língua materna no discurso de professores em formação. Revista Pesquisas em Discurso Pedagógico. Rio de Janeiro, n. 2, 2009.

LÜDKE, Menga (Coord.). O professor e a pesquisa. Campinas, São Paulo: Papirus, 2001.

SOARES, M. As pesquisas nas áreas específicas influenciando o curso de formação de professores. In: ANDRÉ, M. (Org.) O papel da pesquisa na formação e na prática dos professores. Campinas: Papirus, 2001. p. 91-105. 


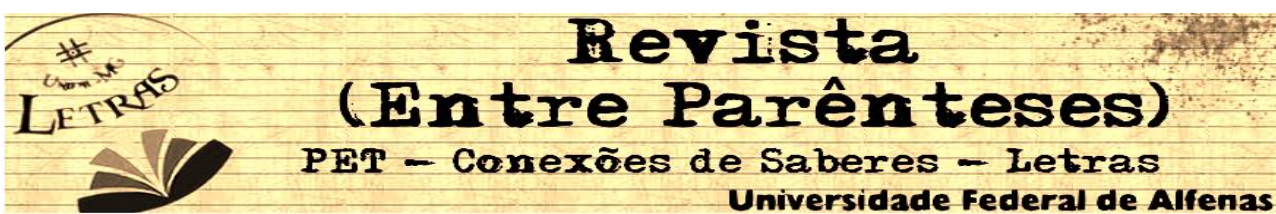

Anexos

1) Quais foram os temas sobre os quais você já pesquisou como proposta de trabalho acadêmico no PIBID?

Gêneros textuais

Oralidade

Leitura

Variaçăo linguística

Retextualização

Ortografia

Estratégias de persuasăo

Livros didáticos

Sequência dídática

Interaçăo pela linguagem

Diretrizes para capacitaçăo docente

Relaçóes entre fala e escrita

Concepçöes de linguagem

Literatura

2) Escreva uma contribuição que a prática da pesquisa tem trazido a/ao:

a) Seu desempenho como aluno de graduação:

Maior conhecimento sobre a lingua $18.60 \%$

Preparação/competência profissional $18,60 \%$

Maior criticidade $13.95 \%$

Preparação para produção de trabalhos acadêmicos $9.30 \%$

Ampliação da reflexão sobre temas diversos $6,97 \%$

Antecipação de conteúdos $6.97 \%$

Enfrentamento de dificuldades $6,97 \%$

Relaçăo entre teoria e prática $6.97 \%$

Percepção da relação entre disciplinas $4.65 \%$

Diferencial entre colegas $2,32 \%$

Identificação de concepçōes inerentes ao trabalho do professor - $2,32 \%$ Permanência do alunos na IES 


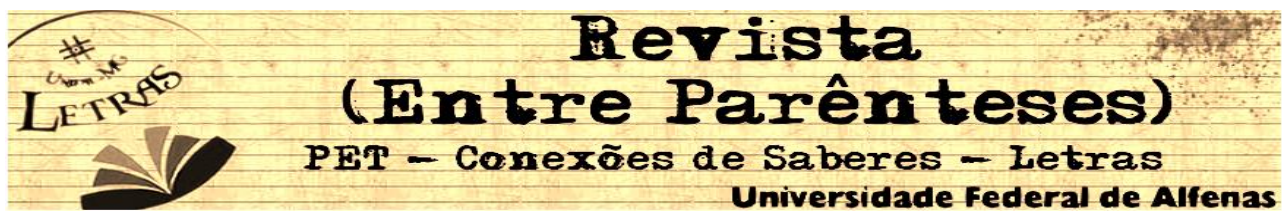

2) Escreva uma contribuiçăo que a prática da pesquisa tem trazido a/ao:

b) Sua atuação nas atividades desenvolvidas no PIBID:

Fundamentação teórica e metodológica

Entendimento acerca da função do professor de português

Segurança

Redimensionamento de práticas

Problematização da prática

Aprendizado do trabalho em equipe

$9,67 \%$

$6,45 \%$

Reflexão acerca da concepção de ensino da lingua

Consciência da relação entre conteúdos

$3,22 \%$

2) Escreva uma contribuição que a prática da pesquisa tem trazido a/ao:

c) Sua formação como professor:

Formação mais ampliada

Ampliação da experiência em sala de aula

Relaçăo entre teoria e prática

Percepção da importância de determinados conteúdos

Produção efetiva do conhecimento

3) Destaque três dificuldades que você tem enfrentado no desenvolvimento de pesquisas no âmbito do PIBID

Falta de tempo

Dificuldade de escrita

Falta de acervo na biblioteca

Orientadores sobrecarregados

Desconhecimento teórico

Desconhecimento metodológico

Dificuldade de trabalho em equipe

Não houve dificuldades

Dificuldade de compreensão dos textos teóricos

Dificuldade na coleta dos dados para análise

Falta de espaço para a discussão de temas de pesquisa

Precariedade da escola

Descontinuidade de conteúdos

Dificuldade de estabelecer relação entre teoria e prática 


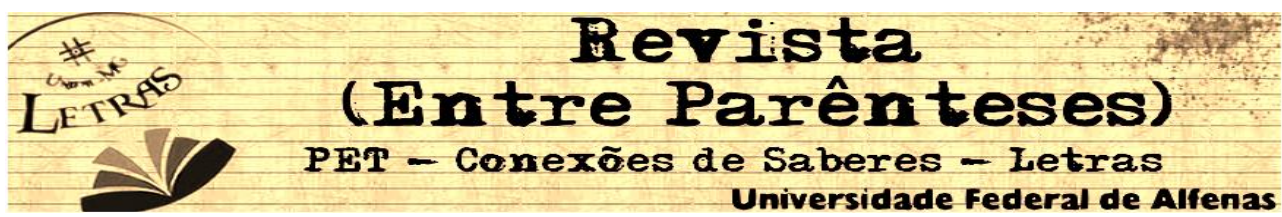

4) Apresente três sugestőes para tornar a prática da pesquisa mais efetiva e eficaz no âmbito do PIBID.

Ampliaçăo do número de orientadores

Maior organização do tempo $11,53 \%$

Criaçăo de mais núcleos de estudo $9,61 \%$

Realização de mais oficinas $9,61 \%$

Ampliação do acervo bibliográfico à disposição $7,69 \%$ Abertura de mais espaço para a troca de ideias $5.76 \%$

Realização de mais pesquisas práticas $5,76 \%$

Contato mais intenso com os alunos $5.76 \%$

Continuidade das pesquisas

Mais instrução acerca das metodologias de pesquisa $3,84 \%$

Maior contato com autores

Mais aplicaçăo dos referenciais teóricos estudados

Maior organização das orientaçöes

Realização de maior quantidade de pesquisas teóricas 
3) Destaque três dificuldades que você tem enfrentado no desenvolvimento de pesquisas no âmbito do PIBID

Falta de tempo

$21,15 \%$

Dificuldade de escrita

$11,53 \%$

Falta de acervo na biblioteca

Orientadores sobrecarregados

Desconhecimento teórico

Desconhecimento metodológico

Dificuldade de trabalho em equipe

Não houve dificuldades

Dificuldade de compreensão dos textos teóricos

$$
3,84 \%
$$

Dificuldade na coleta dos dados para análise

$$
3,84 \%
$$

Falta de espaço para a discussão de temas de pesquisa $3,84 \%$

Precariedade da escola

Descontinuidade de conteúdos

$1,92 \%$

Dificuldade de estabelecer relação entre teoria e prática

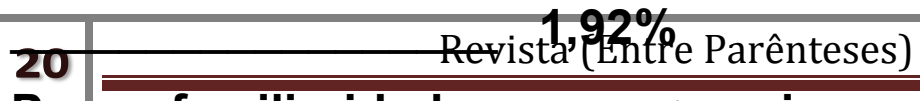

Pouca familiaridadiescroma-presquisa 
4) Apresente três sugestões para tornar a prática da pesquisa mais efetiva e eficaz no âmbito do PIBID.

Ampliação do número de orientadores $21,15 \%$

Maior organização do tempo $11,53 \%$

Criação de mais núcleos de estudo $9,61 \%$

Realização de mais oficinas

Ampliação do acervo bibliográfico à disposição $7,69 \%$

Abertura de mais espaço para a troca de ideias $5,76 \%$

Realização de mais pesquisas práticas $5,76 \%$

Contato mais intenso com os alunos $5,76 \%$

Continuidade das pesquisas

Mais instrução acerca das metodologias de pesquisa $3,84 \%$

Maior contato com autores

Mais aplicação dos referenciais teóricos estudados $3,84 \%$

Maior organização das orientações $1,92 \%$

Realização de maior quantidade de pesquisas teóricas $1,92 \%$

Sem sugestões

21 Revista (Entre Parênteses)

$1,92 \%$ 


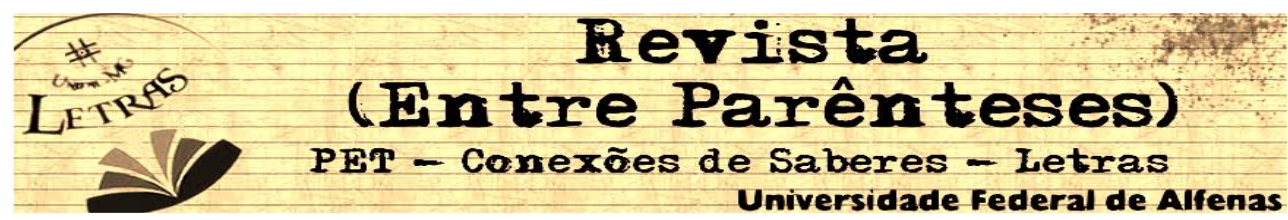

